\title{
Monitoring and driving force analysis of spatial and temporal change of water area of Hongjiannao lake from 1973 to 2019
}

\author{
Hongye $\mathrm{Cao}^{1}$ and Ling $\operatorname{Han}^{1}$ \\ ${ }^{1}$ Chang'an University
}

July 20, 2020

\begin{abstract}
Hongjiannao lake is the largest desert fresh water lake in China and the largest breeding and habitat of relict gulls in the world. On the basis of remote sensing images, a high-precision long-time series lake area continuous monitoring data set was constructed from 1973 to 2019. On this basis, the temporal and spatial evolution law of lake area and the coupling relationship with natural factors and human activities were studied. At the same time, the effectiveness monitoring of protection measures implemented since 2012 was realized. The results show that: (1) from 1973 to 2019, the area of Hongjiannao lake experienced three stages (relatively stable period (1973-1997) - shrinking period (1997-2015) - expanding period (2015-2019)). (2) The shrinkage of Hongjiannao lake is mainly caused by human factors, followed by natural factors. Among them, human factors are mainly composed of the upstream river construction reservoir, industrial development water and the increase of water demand for vegetation growth. (3) For the first time, the preliminary results of the protection measures implemented since 2012 are analyzed. It is mainly reflected in the first positive growth of Hongjiannao Lake area since the long-term shrinkage in 2016. This phenomenon is mainly caused by measures such as artificial precipitation increase and ecological water replenishment on the surface of upstream reservoir. Climate change (high evaporation and low precipitation) and human activities (upstream water conservancy project construction, coal mining, highway construction around the lake, irrigation water consumption, etc.) are the key factors leading to the change of lake water area in the shrinking period. It is suggested that artificial precipitation increase and surface ecological water supplement normalization should be carried out in the study area, as well as scientific and reasonable utilization of water resources in the basin to effectively restrain the shrinking of Hongjiannao lake area, so as to achieve long-term sustainable restoration of wetland ecology.
\end{abstract}

\section{Hosted file}

Manuscript.docx available at https://authorea.com/users/344500/articles/470994-monitoringand-driving-force-analysis-of-spatial-and-temporal-change-of-water-area-of-hongjiannaolake-from-1973-to-2019

\section{Hosted file}

figure.doc available at https://authorea.com/users/344500/articles/470994-monitoring-anddriving-force-analysis-of-spatial-and-temporal-change-of-water-area-of-hongjiannao-lakefrom-1973-to-2019

\section{Hosted file}

table.doc available at https://authorea.com/users/344500/articles/470994-monitoring-anddriving-force-analysis-of-spatial-and-temporal-change-of-water-area-of-hongjiannao-lakefrom-1973-to-2019 